Brazilian Journal

of Chemical

ISSN 0104-6632

Engineering

Printed in Brazil

www.abeq.org.br/bjche

Vol. 34, No. 02, pp. 429 - 438, April - June, 2017

dx.doi.org/10.1590/0104-6632.20170342s20150541

\title{
TEMPERATURE, pH AND CARBON SOURCE AFFECT DRASTICALLY INDOLE ACETIC ACID PRODUCTION OF PLANT GROWTH PROMOTING YEASTS
}

\author{
A. S. de A. Scarcella ${ }^{1}$, R. Bizarria Junior ${ }^{2}$, R. G. Bastos ${ }^{2}$ and M. M. R. Magri ${ }^{2 *}$ \\ ${ }^{1}$ Universidade de São Paulo, Department of Biochemistry and Immunology, \\ Ribeirão Preto, SP, Brazil. \\ ${ }^{2}$ Universidade Federal de São Carlos, Centro de Ciências Agrárias, \\ Campus Araras, SP, Brazil. \\ Tel: +55 1935432907 \\ E-mail: marcia@cca.ufscar.br
}

(Submitted: August 25, 2015; Revised: February 16, 2016; Accepted: February 26, 2016)

\begin{abstract}
Rhizosphere and phylloplane yeasts are able to produce phytohormones, acting as potential plant growth promoters. The aim of this study was to analyze the production of indole acetic acid (IAA) by yeasts using variations in the culture conditions. The yeasts evaluated were Rhodotorula mucilaginosa and Trichosporon asahii, which were cultivated in a potato broth medium with $20 \mathrm{~g} / \mathrm{L}$ of glucose or sucrose as the carbon source. The cultivation was carried out at $22^{\circ} \mathrm{C}, 25^{\circ} \mathrm{C}$ or $30^{\circ} \mathrm{C}$, and the initial pH was adjusted to $3.0,4.5$ or 6.0 . The cultures were analyzed using a colorimetric technique with Salkowski reagent. The cell count was determined in all of the conditions. The results for T. asahii showed that IAA production with sucrose was superior at $\mathrm{pH} 6.0$, and that with glucose was superior at $\mathrm{pH}$ 4.5. These results indicate an association between the carbon source and medium $\mathrm{pH}$. Rh. mucilaginosa (2F32) presented a high IAA production when compared with T. asahii (3S44 and $4 \mathrm{C} 06)$ or even with other microorganisms referenced in the literature. The highest production $(0.655 \mathrm{~g} / \mathrm{L})$ was obtained at $\mathrm{pH} 6.0$ with glucose as the carbon source. Variations in the culture conditions did not affect the cell growth of the yeasts.

Keywords: Rhodotorula mucilaginosa, Trichosporon asahii, culture conditions, kinetic evaluations
\end{abstract}

\section{INTRODUCTION}

The study of natural processes using autoctonous microorganisms that are able to protect and assist in the development of plants is presented as an alternative for more sustainable agricultural production. However, the lack of knowledge about microorganism function in the rhizosphere continues to be a challenge for scientists (Tiedje et al., 1999; Fitter et al., 2005; Torsvik and Ovreas, 2002; Van der Heijden et al., 2008; Maron et al. 2011). One of the goals in soil microbe studies is to stimulate microorganisms via agroecosystem management or by employing bio-products with beneficial species that are able to support plant production.

The challenge in this area is the expansion of knowledge regarding the behavior of microorganisms in the rhizosphere and the discovery of how they can assist the plant production process, contribute to the balance of the ecosystem and minimize the use of toxic products in the environment, such as fungicides and fertilizers responsible for soil, ground water, river and lake pollution.

The rhizospheric group of microorganisms known as

*To whom correspondence should be addressed 
Plant Growth Promoters (PGP) have the ability to produce compounds capable of stimulating plant growth via a variety of mechanisms, such as the production of phytohormones, biological control of phytopathogens and plant resistance induction, as well as the solubilization of phosphate and available minerals in the soil solution, promoting better nutrition for plants. Various studies in the literature have reported that rhizospheric microorganisms, especially rhizobacteria, show excellent results in promoting plant growth (Ahemad and Kibret, 2014; Lugtenberg and Kamilova, 2009; Myresiotis et al., 2014; Prashar et al., 2014). Another extensively studied group is the endophytic microorganisms, similar to the rhizobacteria, with the potential for use in various other economic crops (Brader et al., 2014; Hallmann et al., 1997; Rosenblueth and Martinez Romero, 2006; Shen et al., 2014).

Yeasts are unicellular fungi that can also be found in the rhizosphere of plants, but in smaller numbers compared to bacteria and filamentous fungi; however, little information is known about their function in this ecosystem. A wide variety of yeasts present characteristics that promote plant growth (Cloete et al., 2009; Limtong et al., 2014; Nutaratat et al., 2014) via the control of plant pathogens (El-Tarabily, 2004; El-Tarabily and Sivasithamparam, 2006; Korres et al., 2011; Rosa et al., 2010), the production of phytohormones (Nassar et al., 2005), the solubilization of phosphate (Hesham and Mohamed, 2011; Falih and Wainwright, 1995; Mirabal Alonso et al., 2008; Mundra et al., 2011), the oxidation and mineralization of nitrogen and sulfur compounds (Falih and Wainwright, 1995), the production of siderophores (Sansone et al., 2005) and the stimulation of root colonization by mycorrhizal fungi (Mirabal Alonso et al., 2008; Vassileva et al., 2000).

One of most important mechanisms applied by PGP is phytohormone production. The auxin group is a class of plant hormones known to stimulate responses in plants both quickly and in the long term. Indole acetic acid is a type of auxin produced by many groups of microorganisms, including bacteria (Ahmed and Hasnain, 2010; Tsavkelova et al., 2007), filamentous fungi (Manici et al., 2014; Hasan, 2002; Sirrenberg et al., 2007), and yeasts (Nassar et al., 2005).

The aim of this study was to evaluate the production of indole acetic acid by the yeasts isolated from the rhizosphere and phylloplane of maize and sugar cane and to evaluate the influence of temperature, $\mathrm{pH}$ and carbon source on production.

\section{MATERIALS AND METHODS}

\section{Microorganisms}

The yeasts evaluated in this study were isolated from sugarcane and maize in São Paulo State, Brazil. The strains consisted of 2 epiphytic yeasts from sugar cane leaves (Rhodotorula mucilaginosa - 2F32) and stems (Trichosporon asahii - 4C66), plus one rhizospheric yeast isolated from maize (Trichosporon asahii - 3S44). The choice of these isolates was based on preliminary screening of strains able to produce indole acetic acid (data not published), employing colorimetric analysis, according to Gordon and Weber (1951), as mentioned following in this manuscript. The yeasts were maintained in a culture collection at the Laboratory of Agricultural and Molecular Microbiology (LAMAM), Federal University of São Carlos, Brazil. The culture was kept in YEPD medium and stored at $8^{\circ} \mathrm{C}$ until the start of the tests.

\section{Temperature, $\mathrm{pH}$ and Carbon Source conditions}

Yeast inoculum was prepared by transferring one loop of the colony into $10 \mathrm{~mL}$ of YEPD broth, which was incubated in a shaker at $160 \mathrm{rpm}, 30^{\circ} \mathrm{C}$ for 3 days. One milliliter of a suspension of concentration $1 \times 10^{7}$ cells $/ \mathrm{ml}$ from this culture was used as the inoculum. The yeast strains were cultivated in Erlenmeyer flasks (500 $\mathrm{mL}$ ) containing $200 \mathrm{~mL}$ of potato broth (infusion from potatoes) supplemented with $0.54 \mathrm{~g} / \mathrm{L}$ of tryptophan and $20 \mathrm{~g} / \mathrm{L}$ of the carbon source, either glucose or sucrose. The medium $\mathrm{pH}$ was modified according to the treatment to $3.0,4.5$ or 6.0 with $0.1 \mathrm{~N} \mathrm{HCl}$ before sterilization. The culture flasks were incubated on an orbital shaker at 160 $\mathrm{rpm}$ for 4 days at 22,25 or $30^{\circ} \mathrm{C}$. The medium was used as a control. The samples were taken for analysis every 12 hours for a total of 96 hours. At each sample time, 10 $\mathrm{mL}$ of the culture suspension was taken and the amount of cells was determined with a Neubauer chamber. The cell number was used as an estimate of cell mass $(R h$. mucilaginosa $-1 \times 10^{6}$ cells $/ \mathrm{mL}=0.85 \mathrm{~g}$ of dry biomass and T. asahii $-1 \times 10^{6}$ cells $/ \mathrm{mL}=2.1 \mathrm{~g}$ of dry biomass). Indole acetic acid production was determined by colorimetric method (Gordon and Weber, 1951), using the remainder of the sample, as described below.

\section{Indole acetic acid (IAA)}

The samples were centrifuged at $3000 \mathrm{rpm}$ for $5 \mathrm{~min}$, and $1 \mathrm{~mL}$ of culture supernatant was mixed with $1 \mathrm{~mL}$ of Salkowski reagent (12 g. $\mathrm{L}^{-1} \mathrm{FeCl}_{3}$ in $7.9 \mathrm{M} \mathrm{H}_{2} \mathrm{SO}_{4}$ ) (Gordon and Weber, 1951), followed by an incubation for 30 minutes to complete pink-red color development. The color intensity was determined as $\mathrm{A}_{530}$ using a spectrophotometer (Thermo Electron Corporation, USA). The IAA concentration of the sample was compared with a linear calibration curve obtained from a commercial IAA standard using the performance of three replicates.

\section{Kinetic analysis}

The growth curves were plotted for the experimental 
conditions, and the kinetic parameters were calculated according to Ahmad and Holland (1995). The maximum specific growth rates were estimated from the slope of semi-log plots of biomass concentration vs. time, while productivity was estimated from the IAA profile curves.

Statistical analysis

All of the data reported in this study are the mean of the values from three replicates. Differences between the treatments were tested by Analysis of Variance (ANOVA), and the mean values between treatments were compared by Tukey Test at $p=0.05$. Statistical analysis of the data was performed using the statistical computer program STATISTICA 6.0 (Statsoft, Tulsa-OK, USA, 2003).

\section{RESULTS}

Rh. mucilaginosa (strain 2F32) had a significantly higher production of IAA compared to the strains of $T$. asahii (3S44 and 4C06) in all of the tested conditions (Figure 1). The 3S44 strain showed a higher production of IAA compared to the 4C06 strain, although they are the same species. Even with the differences in production, the factors evaluated ( $\mathrm{pH}$, carbon source and temperature) presented the same influences, with an increase or decrease in IAA production for both strains of $T$. asahii.

The $\mathrm{pH}$ of the medium showed a significant influence on the production of IAA by T. asahii, with superior results at an initial $\mathrm{pH}$ of 4.5 and a maximum output of approximately $0.03 \mathrm{~g} / \mathrm{L}$ in the medium containing $2 \%$ of glucose (in terms of mass) as the carbon source. The medium at $\mathrm{pH} 3$ did not allow for the production of IAA by the yeast, and at $\mathrm{pH} 6$ the production was very low, not exceeding $0.0027 \mathrm{~g} / \mathrm{L}$. For Rh. mucilaginosa (2F32), the highest production of IAA $(0.655 \mathrm{~g} / \mathrm{L})$ was obtained at $\mathrm{pH} 6$ in the medium that contained glucose as the carbon source (Figure 1).

According to Figure 2, the presence of sucrose in the medium promoted a higher production of IAA compared to glucose (both at initial $\mathrm{pH}$ of 6.0), with a maximum production close to $0.07 \mathrm{~g} / \mathrm{L}$. For Rh. mucilaginosa, glucose provided the maximum amount produced at any given initial $\mathrm{pH}$ value (Figure 2 and Figure 3). Independent of the carbon source used for Rh. mucilaginosa culture, IAA production occurred during the stationary phase of cell growth (after 24 hours of incubation). For T. asahii strains, however, when sucrose was utilized in the cultivation, the production started during the log phase growth (after 12 hours of incubation) (Figures 1, 2, 3 and 4).

The incubation temperature had an influence on the start of IAA production by the two strains of $T$. asahii; the temperature of $25^{\circ} \mathrm{C}$ provides the production of IAA in less time (after 24 hours), while the culture at $22^{\circ} \mathrm{C}$ causes production delays, which initiated only after 72 hours of incubation. For Rh. mucilaginosa, a temperature of $30^{\circ} \mathrm{C}$ after 60 hours of cultivation, followed by $25^{\circ} \mathrm{C}$ after 24 hours were the culture conditions with the best production results (Figure 4).

The yeast cell growth was not significantly affected by the variation of the factors evaluated. For the yeast Rh. mucilaginous $(2 \mathrm{~F} 32)$, the conditions that provided the best result of IAA production were the same for the better development of the lineage, with a $\mu_{\max }$ (maximum specific growth rate) and IAA productivity of approximately $0.19 \mathrm{~h}^{-1}$ and $12 \mu \mathrm{g} \mathrm{mL}^{-1} \mathrm{~h}^{-1}$, respectively, in the medium containing glucose at an initial $\mathrm{pH}$ of 6 and $25^{\circ} \mathrm{C}$. For $T$. asahii (4C06), the $\mu_{\max }$ was $0.119 \mathrm{~h}^{-1}$ with $2 \%$ glucose, at $\mathrm{pH} 6,25^{\circ} \mathrm{C}$; however, the maximum productivity $(0.64 \mathrm{~g}$ $\mathrm{mL}^{-1} \mathrm{~h}^{-1}$ ) was obtained at an initial of $\mathrm{pH} 4.5$. For T. asahii (3S44), the $\mu_{\max }\left(0.0722 \mathrm{~h}^{-1}\right)$ was observed in a medium with $2 \%$ glucose, at $\mathrm{pH} 6,25^{\circ} \mathrm{C}$, but the maximum productivity $\left(2.49 \mathrm{~g} \mathrm{~mL}^{-1} \mathrm{~h}^{-1}\right)$ in the sucrose medium was observed with an initial $\mathrm{pH}$ of 6 at $30^{\circ} \mathrm{C}$. The optimal cell growth conditions by the specific growth rates were the same for all three of the tested strains, i.e., at $25^{\circ} \mathrm{C}$, in culture medium with glucose as the carbon source and an initial $\mathrm{pH}$ of 6 (Table 1).

\section{DISCUSSION}

The production of IAA by all of strains evaluated occurred during the stationary growth phase when glucose was utilized as the carbon source. This finding has already been observed in other microorganisms, such as bacteria (Azospirillum sp. and Arthrobacter sp. (Cacciari et al., 1989), Streptomyces albidoflavus (Narayana et al., 2009), Rhizobium sp. (Nalini and Rao, 2014)) and mold (Aspergillus niger (Bilkay et al., 2010)). The production of IAA during the stationary phase must be related to the decrease of carbon and yeast nutritional stress. The results for the T. asahii strains showed that sucrose as the carbon source yielded higher IAA production and that the production started during the log phase. This result could have occurred due to the yeast having suffered nutritional stress when using sucrose as a carbon source since the production of invertase is required for obtaining glucose by cells; the efficiency of this process was not determined in this study.

The maximum IAA productivity by $R h$ mucilaginosa (2F32) was over ten times higher than the maximum value obtained with the $T$. asahii strains, a finding that was observed in all of the experimental conditions.

This study is not the first to show IAA production results for the yeast species Rh. mucilaginosa and $T$. asahii. Xin et al. (2009) obtained endophytic strains of Rh. mucilaginosa from Populus trees and evaluated their ability to produce IAA. These authors evaluated two strains and observed significant differences in their IAA production, such that PTD2 reached $18 \mathrm{mg}$ of IAA $/ \mathrm{mg}$ of dry cell mass and PTD3 produced less than $10 \mathrm{mg}$ of IAA/mg of dry cell mass. In this study, differences were observed in IAA 

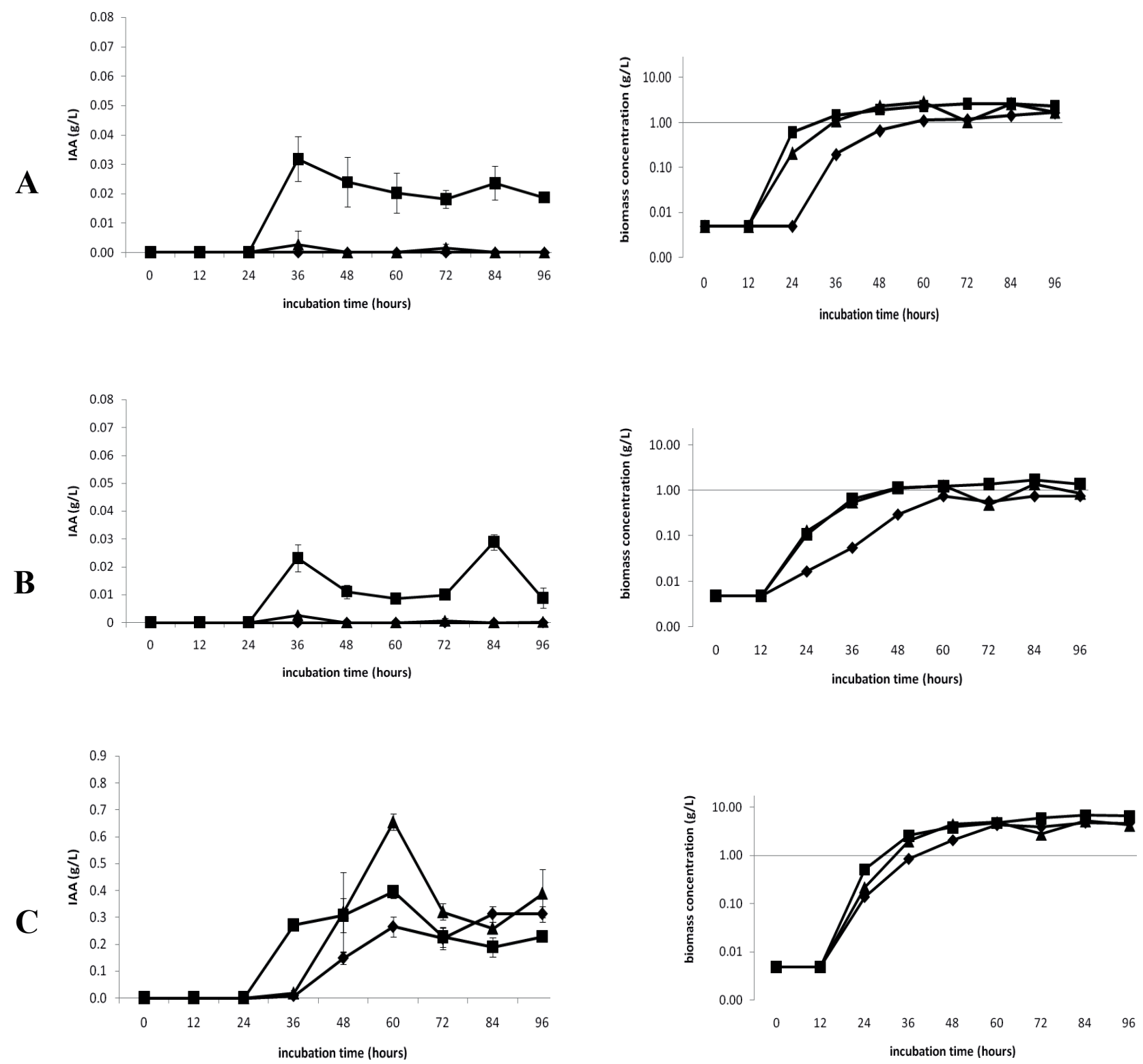

Figure 1. IAA production and cell biomass concentration of T. asahii (A - strain 3S44 and B - strain 4C06) and Rh. mucilaginosa (C -

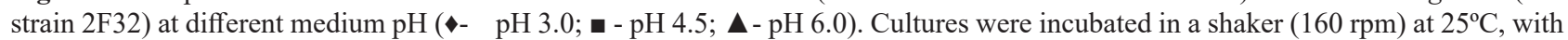
$2 \%$ glucose as the carbon source. Data was the means of three replicates. Bars at each point indicate \pm SE.

Table 1. Maximum specific growth rate $\left(\mu_{\max }\right)$ for yeast strains in the culture conditions evaluated.

\begin{tabular}{ccccc}
\hline \multirow{2}{*}{ Yeast strain } & \multirow{2}{*}{$\boldsymbol{\mu}_{\max }\left(\mathbf{h}^{-1}\right)$} & \multicolumn{3}{c}{ culture conditions } \\
\cline { 3 - 5 } Rh. mucilaginosa $(2 \mathrm{~F} 32)$ & 0.19 & Temperature & $\mathbf{p H}$ & Carbon source \\
\hline T. asahii (4C06) & 0.119 & $25^{\circ} \mathrm{C}$ & 6.0 & glucose \\
\hline T. asahii (3S44) & 0.072 & $25^{\circ} \mathrm{C}$ & 6.0 & glucose \\
\hline
\end{tabular}



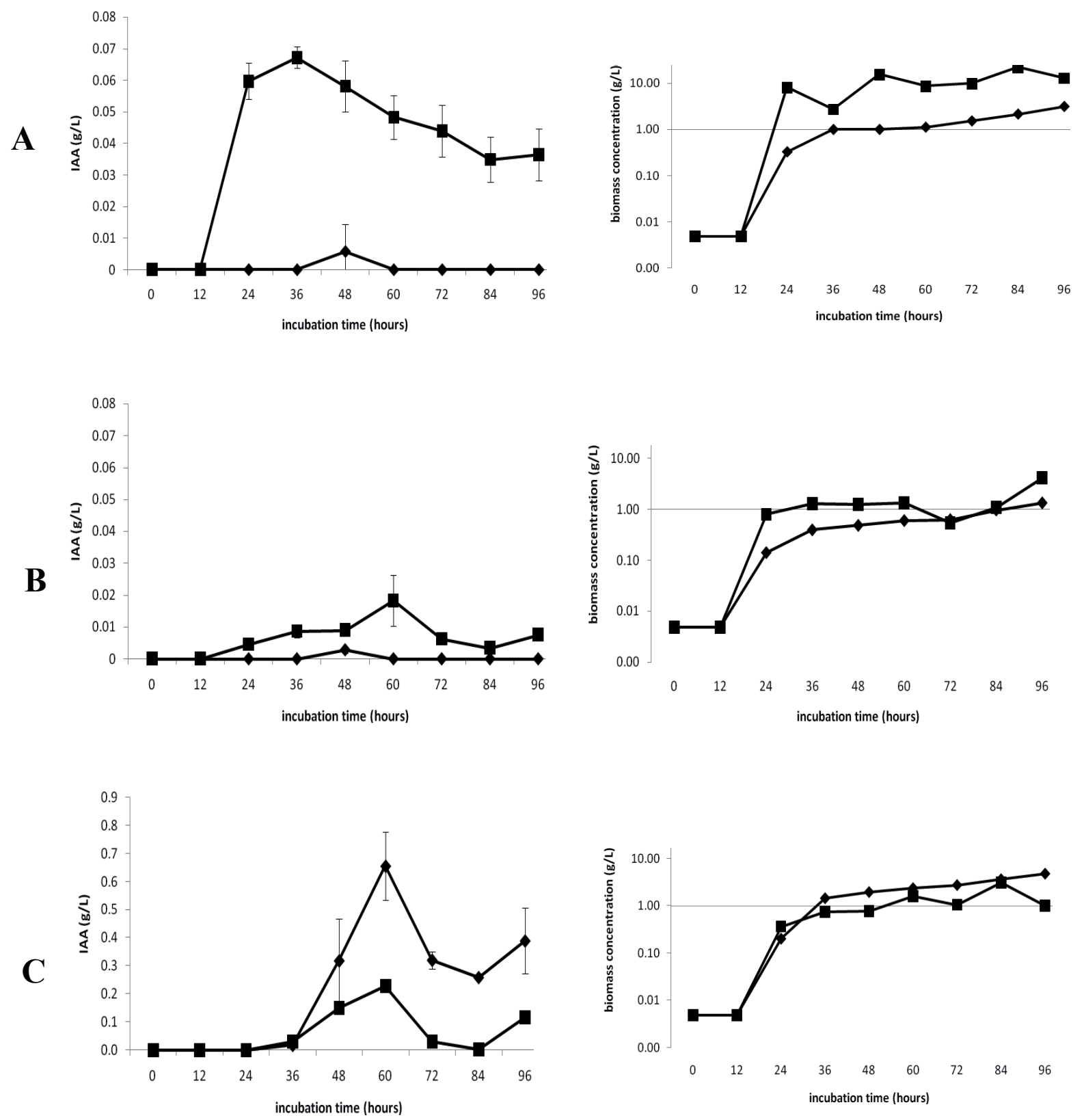

Figure 2. IAA production and cell biomass concentration of T. asahii (A - strain 3S44 and B - strain 4C06) and Rh. mucilaginosa (C - strain 2 F32) with different carbon sources $(-2 \%$ glucose; $-2 \%$ sucrose). Cultures were incubated in a shaker $(160 \mathrm{rpm})$ at $\mathrm{pH}$ $6.0,25^{\circ} \mathrm{C}$. Data was the means of three replicates. Bars at each point indicate $\pm \mathrm{SE}$.

Table 2. IAA yield ( $\mathrm{Y}_{\mathrm{IAA}}$ ) from a given carbon source, for yeast strains in the culture conditions evaluated.

\begin{tabular}{|c|c|c|c|c|c|}
\hline \multirow{2}{*}{ Yeast strain } & \multirow{2}{*}{$Y_{\mathrm{IAA}}(\mu \mathrm{g} / \mathrm{ml} / \mathbf{h})$} & \multicolumn{4}{|c|}{ culture conditions } \\
\hline & & Temperature & pH & Carbon source & Time (hours) \\
\hline Rh. mucilaginosa (2F32) & 12 & $25^{\circ} \mathrm{C}$ & 6.0 & glucose & 60 \\
\hline T. asahii (4C06) & 0.64 & $25^{\circ} \mathrm{C}$ & 4.5 & glucose & 36 \\
\hline T. asahii (3S44) & 2.49 & $30^{\circ} \mathrm{C}$ & 6.0 & sucrose & 24 \\
\hline
\end{tabular}


A

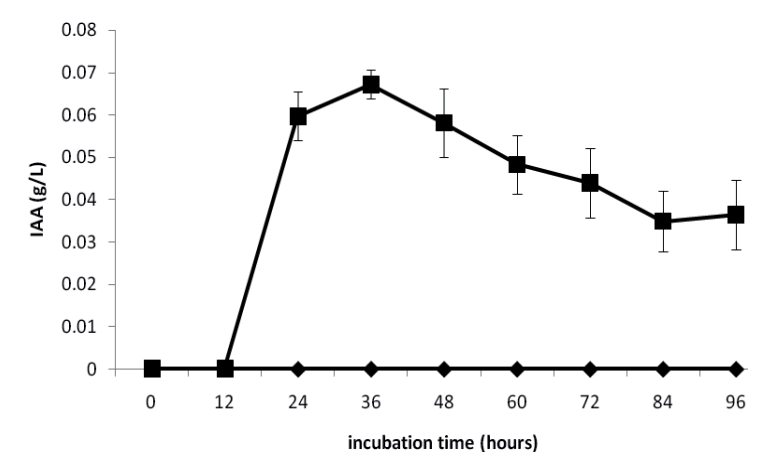

B
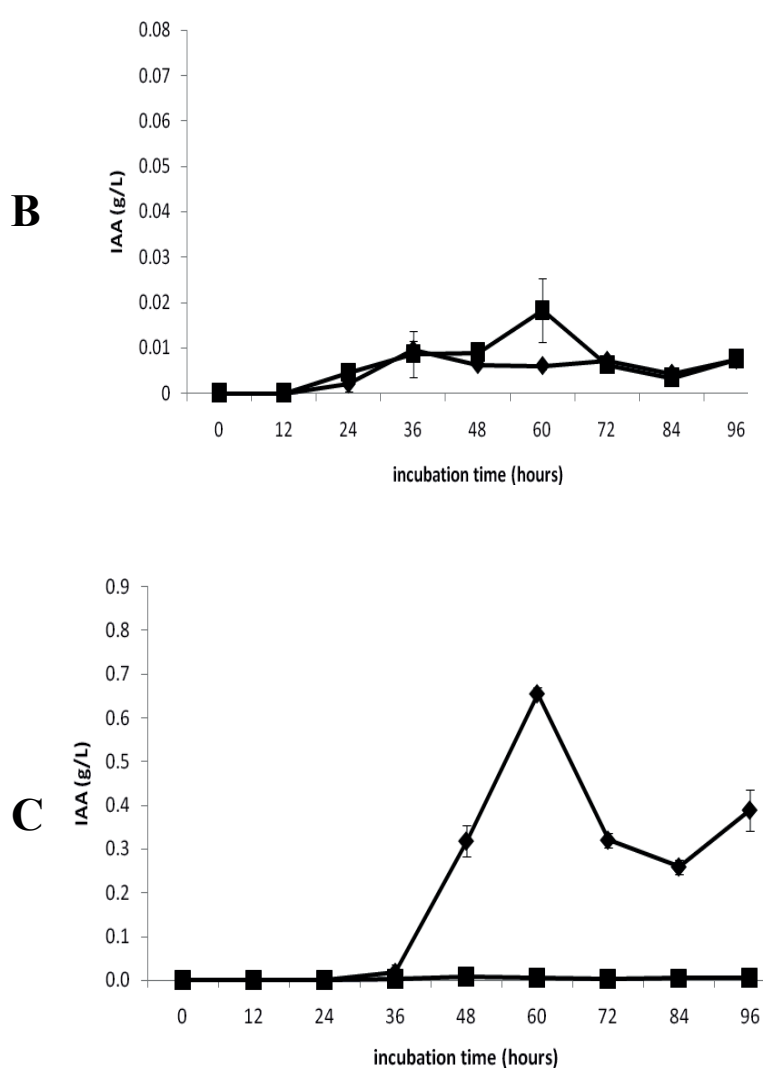
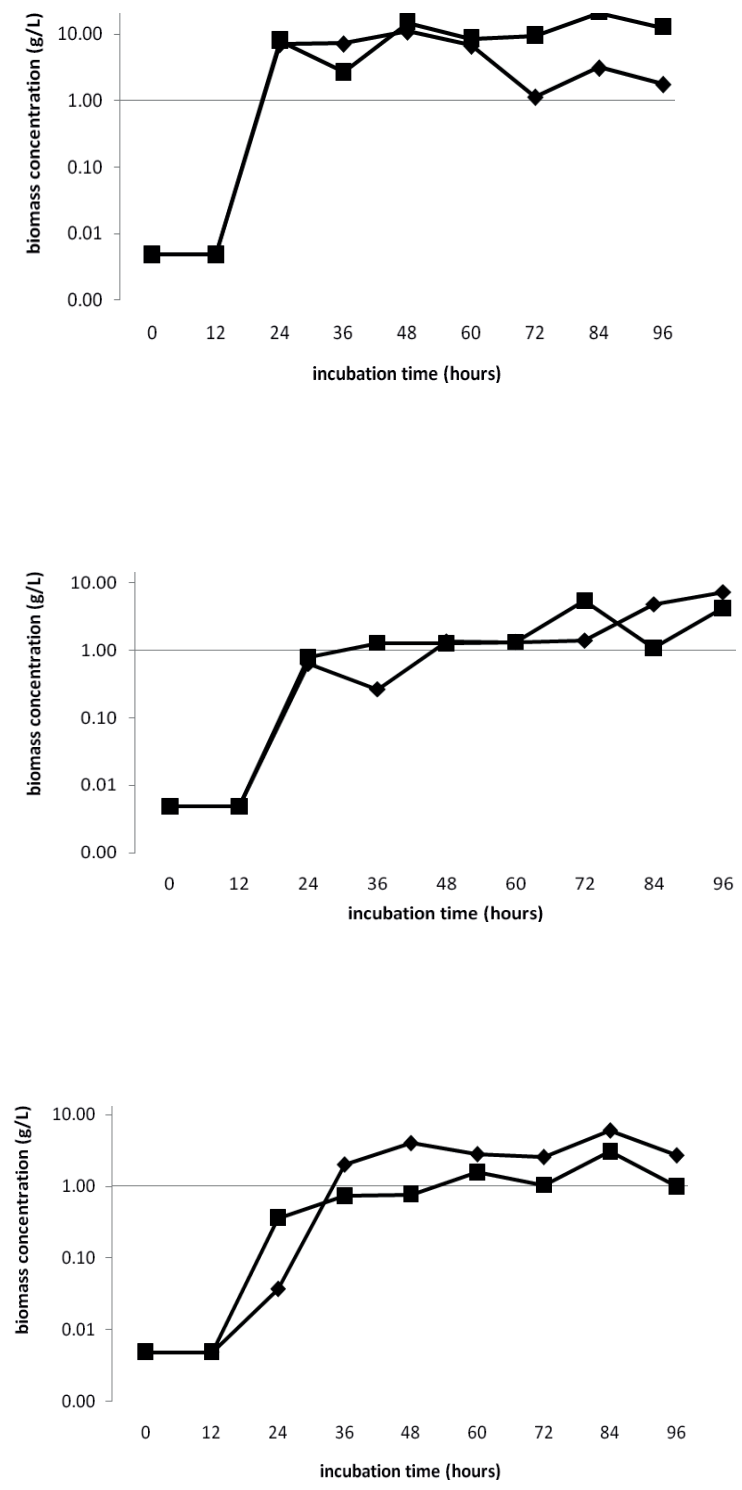

Figure 3. IAA production and cell biomass concentration of T. asahii (A - strain 3S44 and $\mathrm{B}$ - strain 4C06) and Rh. mucilaginosa (C - strain $2 \mathrm{~F} 32)$ at different $\mathrm{pH}(-\mathrm{pH} 4.5 ;-\mathrm{pH} 6.0)$ with $2 \%$ sucrose as the carbon source. Cultures were incubated in a shaker (160 $\mathrm{rpm})$ at $25^{\circ} \mathrm{C}, \mathrm{pH}$ 6.0. Data was the means of three replicates. Bars at each point indicate $\pm \mathrm{SE}$.

production between the strains of $T$. asahii, such that strain 3S44 (isolated from the rhizosphere) showed better results compared with strain 4C06 (isolated from the stem). Limtong and Koowadjanakul (2012) isolated yeasts from the phylloplane of several plant species and noted that not all of the strains within the same species had the ability to produce IAA. Variations in IAA biosynthesis between strains within the same species have been reported by other investigators (Nutaratat et al., 2014; Ruanpanun et al., 2010; Sun et al., 2014; Tsvkelova et al., 2006).

Results suggests that temperature, $\mathrm{pH}$ and carbon source did not influence the cell growth for strains, indicating microbial stability in the different conditions. This adaptability is a very important feature for microorganisms with potential use in the scaling up of biotechnological processes, whether they are industrial or agricultural. For Rh. mucilaginosa (2F32), the results indicate that the optimum growth conditions also result in high IAA productivity. For the strains of T. asahii, the conditions for higher productivity were not the same as those for the maximum growth rate, in which one of the variables was changed, such as $\mathrm{pH}$ (for 4C06 strain), sugar source or temperature (for 3S44 strain). Sun et al. (2014) evaluated temperature and $\mathrm{pH}$ variations on IAA production by 

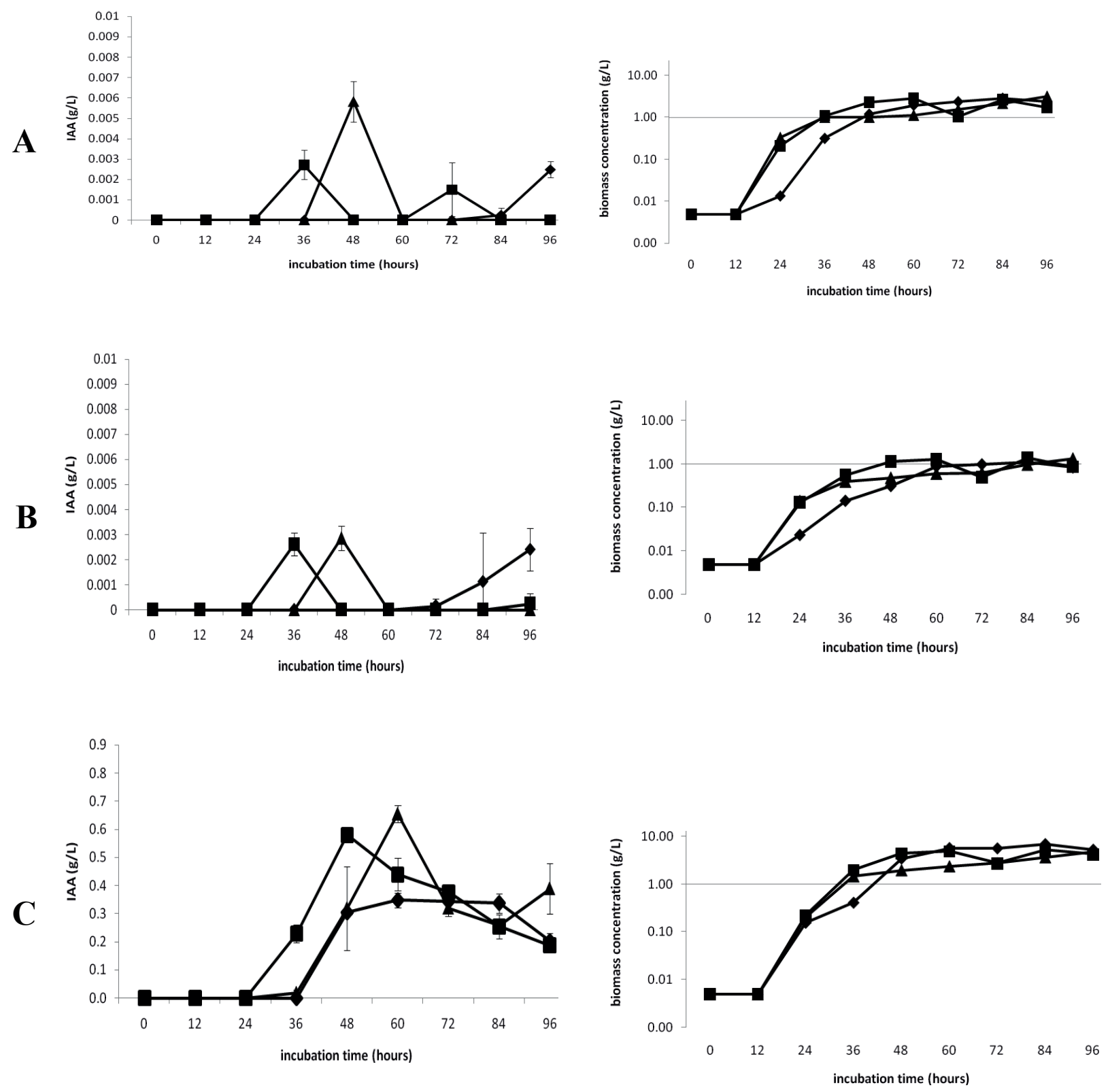

Figure 4. IAA production and biomass concentration of T. asahii (A - strain 3S44 and $\mathrm{B}-$ strain 4C06) and Rh. mucilaginosa $(\mathrm{C}-$ strain $2 \mathrm{~F} 32)$ at different temperatures $\left(-22^{\circ} \mathrm{C}\right.$; $\left.-25^{\circ} \mathrm{C} ; \boldsymbol{\Delta}-30^{\circ} \mathrm{C}\right)$. Cultures were incubated in a shaker $(160 \mathrm{rpm})$ at $\mathrm{pH} 6.0$, with glucose as the carbon source. Data was the means of three replicates. Bars at each point indicate $\pm \mathrm{SE}$.

yeasts isolated from a carnivorous plant (Drosera indica) and noted that the results were different for each strain evaluated. The authors reported that the yeasts were unable to produce IAA under alkaline conditions, and the majority of the strains presented high production values at $28^{\circ} \mathrm{C}$ compared to $37^{\circ} \mathrm{C}$ and $16^{\circ} \mathrm{C}$. Yeast strains have different responses to environmental conditions, and these variations affect the production of phytohormones.

According to studies in the literature, IAA production is directly related to morphological changes in the yeast cells (production of pseudo-hyphae/stranded), which in turn are related to a "search" for nutrients (in the case of nutritional stress conditions) or host tissue invasion (for pathogenic yeasts) (Antonini and Sudbery, 2004; Prusty et al., 2004; Rao et al., 2010). In this study, however, IAA was produced under optimal or very close to ideal growing conditions. Furthermore, no cell morphological changes were observed during periods of higher IAA production, indicating that in this case there was no direct relationship between this production and the filamentation in the evaluated yeast strains. 


\section{CONCLUSIONS}

Temperature, $\mathrm{pH}$ and carbon source can influence the IAA production of yeast strains of Rhodotorula mucilaginosa and Trichosporon asahii; however, these factors did not significantly influence cell growth. IAA production, when glucose was used as the carbon source, started after the initial stationary growth phase of yeast development. For Rh. mucilaginosa, the maximum production was obtained in the most appropriate conditions for yeast development. No relationship between the IAA production and morphological changes in the yeast cells was observed.

Our future goals include testing these strains in plant experiments to observe whether they are able to promote plant growth in vivo, and improving the use of these beneficial yeasts as an agricultural tool for more sustainable field production.

\section{ACKNOWLEDGEMENTS}

This study was supported by the Fundação de Apoio à Pesquisa do Estado de São Paulo (FAPESP) with fellowship grants to A.S.A. Scarcella (n ${ }^{\circ}$ 2011/18676-5) and R. Bizarria Junior ( $\mathrm{n}^{\circ}$ 2013/02421-3) and research support (n⿳⺈冂大 2011/02322-0).

\section{REFERENCES}

Ahemad M., Kibret M., Mechanisms and applications of plant growth promoting rhizobacteria: Current perspective. Journal of King Saud University - Science 26, 1, (2014).

Ahmad M.N., Holland C.R., Growth kinetics of singlecell protein in batch fermenters. Journal of Food Enginneering, 26, 443 (1995).

Ahmed A., Hasnain H., Auxin-producing Bacillus sp.: Auxin quantification and effect on the growth of Solanum tuberosum. Pure Applied Chemistry. 82, 313, (2010).

Bilkay S., Karakoç S., Aksoz N., Indole-3-acetic acid and gibberellic acid production in Aspergillus niger. Turkish Journal of Biology, 34, 313 (2010).

Brader G., Compant, S., Mitter B., Trognitz F., Sessitsch A., Metabolic potential of endophytic bacteria. Current Opinion in Biotechnology Science, 27, 30 (2014).

Cacciari D., Lippi D., Pietrosanti T., Petrosanti W., Phytohormone-like substances produced by single and mixed diazotrophic cultures of Azospirillum and Arthrobacter. Plant Soil, 115, 151 (1989)

Ceccato-Antonini S.R., Sudbery P.E., Filamentous growth in Saccharomyces cerevisiae. Brazilian Journal of Microbiology, 35, 173 (2004).
Cloete K., Valentine A., Stander M., Blomerus L., Botha A., Evidence of symbiosis between the soil yeast Cryptococcus laurentii and a sclerophyllous medicinal shrub, Agathosma betulina (Berg.) Pillans. Microbial Ecology, 57, 624 (2009).

El-Tarabily K.A., Suppression of Rhizoctonia solani diseases of sugar beet by antagonistic and plant growthpromoting yeasts. Journal of Applied Microbiology, 96, 69 (2004).

El-Tarabily K.A., Sivasithamparam K., Potential of yeasts as biocontrol agents of soil-borne fungal plant pathogens and as plant growth promoters. Mycoscience, 47, 25 (2006).

Falih A.M., Wainwright M., Nitrification, S-oxidation and P-solubilization by the soil yeast Williopsis californica and by Saccharomyces cerevisiae. Mycology Research, 99, 200 (1995).

Fitter A.H., Gillian C.A., Hollingworth K., Kleczkowski A., Twyman R.M., Pitchford J.W., Biodiversity and ecosystem function in soil. Functional Ecology, 19, 369 (2005).

Gordon S.A., Weber R.P., Colorimetric estimation of indoleacetic acid. Plant Physiology, 26, 192 (1951).

Hallmann J., Quadt-Hallmann A., Mahaffee W.F., Kloepper J.W., Bacterial endophytes in agricultural crops. Canadian Journal of Microbiology, 43, 895 (1997).

Hesham A.L., Mohamed H., Molecular genetic identification of yeast strains isolated from egyptian soils for solubilization of inorganic phosphates and growth promotion of corn plants. Journal of Microbiology and Biotechnology, 21, 55 (2011).

Korres A.M.N., Buss D.S., Ventura J.A., Fernandes, P.M.B., Candida krusei and Kloeckera apis inhibit the causal agent of pineapple fusariosis, Fusarium guttiforme. Fungal Biology, 115, 1251 (2011).

Limtong S., Kaewwichian R., Yongmanitchai W., Kawasaki H., Diversity of culturable yeasts in phylloplane of sugarcane in Thailand and their capability to produce indole-3-acetic acid. World Journal of Microbiology and Biotechnology, 30, 1785 (2014).

Limtong S., Koowadjanakul N., Yeasts from phylloplanes and their capability to produce indole-3-acetic acid. World Journal of Microbiology and Biotechnology, 28, 3323 (2012).

Lugtenberg B., Kamilova F., Plant-growth-promoting rhizobacteria. Annual Review of Microbiology, 63, 541 (2009).

Manici L.M., Kelderer M., Caputo F., Mazzola M., Auxinmediated relationships between apple plants and root inhabiting fungi: impact on root pathogens and potentialities of growth-promoting populations. Plant Pathology DOI: 10.1111/ppa.12315 (2014). 
Maron P.A., Mougel C., Ranjard L., Soil microbial diversity: methodological strategy, spatial overview and functional interest. Comptes Rendus Biologies, 334, 403 (2011).

Mirabal Alonso L., Kleiner D., Ortega E., Spores of the mycorrhizal fungus Glomus mosseae host yeasts that solubilize phosphate and accumulate polyphosphates. Mycorrhiza, 18, 197 (2008).

Mundra S., Arora R., Stobdan T., Solubilization of insoluble inorganic phosphates by novel temperature, $\mathrm{pH}$ and salt tolerant yeast, Rhodotorula $\mathrm{sp}$. PS4, isolated from seabuckthorn rhizosphere, growing in cold desert of Ladakh, India. World Journal of Microbiology and Technology, 27, 2387 (2011).

Myresiotis C.K., Vryzasb Z., Papadopoulou-Mourkidoua E., Effect of specific plant-growth-promoting rhizobacteria (PGPR) on growth and uptake of neonicotinoid insecticide thiamethoxam in corn (Zea mays L.) seedlings. Pest Management Science, (wileyonlinelibrary.com) DOI 10.1002/ps.3919 (2014).

Nalini G., Rao Y.R.K.V.T., Effect of different carbon and nitrogen sources on growth and Indole Acetic Acid production by Rhizobium species isolated from cluster bean (Cyamopsis tetragonoloba (L.)). British Microbiology Research Journal, 4, 1189 (2014).

Narayana K.J., Prabhakar P., Krishna P.S.J., Venketeswarlu Y., Vijayalakshmi M., Indole-3-acetic acid production by Streptomyces albidoflavus. Journal of Biological Research, 11, 49 (2009).

Nassar A., El-Tarabily K., Sivasithamparam K., Promotion of plant growth by an auxin-producing isolate of the yeast Williopsis saturnus endophytic in maize (Zea mays L.) roots. Biology and Fertility of Soils, 42, 97 (2005).

Nutaratat P., Srisuk N., Arunrattiyakom P., Limtong S., Plant growth-promoting traits of epiphytic and endophytic yeasts isolated from rice and sugar cane leaves in Thailand. Fungal Biology, 118, 683 (2014).

Prashar P., Kapoor N., Sachdeva S., Plant growth promoting activities of rhizobacteria associated with tomato in semi-arid region. Advances in Life Sciences and Health, 1, 43 (2014).

Prusty R., Grisafi P., Fink G.R., The plant hormone indoleacetic acid induces invasive growth in Saccharomyces cerevisiae. PNAS, 101, 4153 (2004).

Rao R.P., Hunter A., Kashpur O., Normanly J., Aberrant synthesis of indole-3-acetic acid in Saccharomyces cerevisiae triggers morphogenic transition, a virulence trait of pathogenic fungi. Genetics, 185, 211 (2010).

Rosa M.M., Tauk-Tornisielo S.M., Rampazzo P.E., CeccatoAntonini S.R., Evaluation of the biological control by the yeast Torulaspora globosa against Colletotrichum sublineolum. World Journal of Microbiology and Biotechnology, 26, 1491, (2010).

Rosenblueth M., Martinez-Romero E., Bacterial endophytes and their interactions with hosts. Molecular Plant Microbe Interactions, 19, 827 (2006).

Ruanpanun P., Tangchitsomkid N., Hyde K.D., Lumyong S., Actinomycetes and fungi isolated from plantparasitic nematode infested soils: screening of the effective biocontrol potential, indole-3-acetic acid and siderophore production. World Journal of Microbiology and Biotechnology, 26, 1569 (2010).

Sansone G., Rezza I., Calvente V., Benuzzi D., Tosetti M.I.S.D., Control of Botrytis cinerea strains resistant to iprodione in apple with rhodotorulic acid and yeasts. Postharvest Biololgy and Technology, 35, 245 (2005).

Shen X.Y., Cheng Y.L., Cai C.J., Fan L., Gao J., Hou C.L., Diversity and antimicrobial activity of culturable endophytic fungi isolated from moso bamboo seeds. PLoS ONE 9(4): e95838.doi:10.1371/journal. pone.0095838 (2014).

Sirrenberg A., Göbel C., Grond S., Czempinski N., Ratzinger A., Piriformospora indica affects plant growth by auxin. Physiology Plant, 131, 581 (2007).

Statsoft. Statistica 6.0 for Windows. EUA Software, Tucksa (2003)

Sun P.F., Fang W.T., Shin L.Y., Wei J.Y., Fu S.F., Chou J.Y., Indole-3-Acetic Acid-producing yeasts in the phyllosphere of the carnivorous plant Drosera indica L. PLoS ONE 9(12): e114196. doi:10.1371/journal. pone. 0114196 (2014).

Tiedje J.M., Asuming-Brempong S., Nuèsslein K., Marsh T.L., Shannon J.F., Opening the black box of soil microbial diversity. Applied Soil Ecology, 13, 109 (1999).

Torsvik V., Øvreås L., Microbial diversity and function in soil: from genes to ecosystems. Current Opinion in Microbiology, 5, 240 (2002).

Tsavkelova E.A., Cherdyntseva T.A., Klimova S.Y., Shestakov A.I., Botina S.G., Netrusov A.I., Orchidassociated bacteria produce indole-3-acetic acid, promote seed germination, and increase their microbial yield in response to exogenous auxin. Archives of Microbiology, 188, 655 (2007).

Tsavkelova E.A., Klimova S.Y., Cherdyntseva T.A., Netrusov A.I., Microbial producers of plant growth stimulators and their practical use: a review. Applied Biochemistry and Microbiology, 42, 117 (2006).

Van der Heijden M.G.A., Bardgett R.D., van Straalen N.M., The unseen majority: soil microbes as drivers of plant diversity and productivity in terrestrial ecosystems. Ecology Letters, 11, 296 (2008). 
Vassileva M., Azcon R., Barea J.-M., Vassilev N., Rock phosphate solubilization by free and encapsulated cells of Yarowia lipolytica. Process Biochemistry, 35, 693 (2000).
Xin G., Glawe D., Doty S.L., Characterization of three endophytic, indole- 3-acetic acid-producing yeasts occurring in Populus trees. Mycology Research, 113, 973, (2009). 